\title{
EDUCAÇÃO DAS RELAÇÕES ÉTNICO-RACIAIS E ENSINO DE CIÊNCIAS: UMA EXPERIÊNCIA COM PROFESSORES DO ENSINO FUNDAMENTAL
}

\section{EDUCATION OF ETHNIC-RACIAL RELATIONS AND SCIENCE TEACHING: AN EXPERIENCE WITH FUNDAMENTAL EDUCATION TEACHERS}

Waldemar Borges de Oliveira Júnior Universidade Federal do Pará

Maria da Conceição Gemaque de Matos Universidade Federal do Pará

\section{RESUMO}

Este trabalho é um recorte de uma pesquisa de dissertação de mestrado que tinha como objetivo analisar em que termos um processo formativo de professores de Ciências, contribuiu para sua constituição como professor reflexivo na abordagem da temática das relações étnico-raciais. Nesta produção, apresenta-se os resultados da aplicação de um questionário a quatro professores de Ciências da Escola Municipal de Ensino Fundamental Ribeirão das Neves, localizado no município de Oeiras do Pará e do processo formativo realizado com os mesmos docentes, balizados sobre a temática das relações étnico-raciais na área de Ciências da Natureza. A pesquisa revelou que os professores de Ciências desconheciam a legislação vigente, contudo, a formação realizada com os docentes, corroborou na ampliação dos conhecimentos sobre a temática das relações raciais, assim como os possíveis entrelaces que podem serem realizados nas aulas de Ciências no Ensino Fundamental. Além disso, por meio dos relatos dos professores, identificou-se o quanto foi oportuno para a realização do processo formativo, pois puderam ter acesso aos conhecimentos mínimos sobre a Lei N. 10.639/2003.

Palavras-chave: Ensino de Ciências. Relações étnico-raciais. Formação de professores. Processo formativo. Ensino Fundamental. 


\section{ABSTRACT}

This work is an excerpt from a master's dissertation research that aimed to analyze the terms in which a formative process of science teachers contributed to its constitution as a reflective teacher in addressing the theme of ethnic-racial relations. This work is an excerpt from a master's dissertation research that aimed to analyze the terms in which a formative process of science teachers contributed to its constitution as a reflective teacher in addressing the theme of ethnic-racial relations. In this production, the results of the application of a questionnaire to four science teachers from the Municipal School of Elementary Education Ribeirão das Neves, located in the municipality of Oeiras do Pará, are presented, as well as the training process carried out with the same teachers. ethnic-racial relations in the area of Natural Sciences. In addition, through the teachers' reports, it was identified how opportune it was to carry out the training process, as they could have access to the minimum knowledge about Law No. 10,639 / 2003.

KEY-WORDS: Science teaching. Ethnic-racial relations. Teacher training. Formative process. Elementary School. 


\section{INTRODUÇÃO}

A literatura especializada como Coelho, Coelho e Nascimento (2012) refere da necessidade de formar docentes baseados no respeito à diferença, a pluralidade étnicoracial e voltada para a valorização das diversas identidades dos alunos, tornando-se um compromisso com a sociedade brasileira. Nesse direcionamento, Coelho (2005) alerta, para uma certa ausência na formação de professores para a Escola Básica no que tange a temática das relações raciais, mas que após a aprovação da Lei N. 10.639/2003 (que torna obrigatória a temática da História e Cultura Afro-brasileira nos âmbitos escolares), houve investimentos sobretudo na formação continuada de docentes e que se torna instrumentos para suprir a ausência na formação inicial de professores.

Especificamente no Ensino de Ciências, ainda se observa poucos trabalhos que estudam processos formativos de docentes de Ciências no trato da Lei N. 10.639/2003 (COROZZA; PEDRANCINI, 2014), assim os professores de Ciências não têm sido preparados pedagogicamente com as relações étnico-raciais vividas no cotidiano das escolas brasileiras.

Para Verrangia (2016), os cursos de formação docente quando proporcionados aos professores de Ciências, devem considerar que os conhecimentos científicos foram construídos não somente se pautando dos saberes eurocêntricos, mas também de conhecimentos originários de povos africanos. Quando as formações acontecem de forma consubstanciada e aprofundada, ocorre a desmitificação dos relatos da não contribuição do Continente Africano no desenvolvimento de saberes científicos e sociais. Assim, há uma urgência de discutir nos cursos de formação para professores de Ciências o caráter social do povo do Continente Africano, abordando de forma real a verdadeira História da África.

Do mesmo modo, os processos formativos devem levar em consideração que os valores, conhecimentos, identidades, emoções, memórias, que as pessoas trazem com elas para tais iniciativas têm ações terminante nos complexos processos de construção de saberes (VERRANGIA, 2013). Porém, atualmente pouco se encontra sobre trajetórias e 
identidades de professores de Ciências, no contexto de seu pertencimento étnico-racial e de suas vivências com a cultura.

Desse modo, incluir processos formativos sobre a implementação da Lei $\mathrm{N}$. 10.639/2003, pode possibilitar aos professores de Ciências uma dimensão social, histórica, institucional, grupal e afetiva no ambiente escolar. Esses conjuntos de ações viabilizam avanços na efetivação de direitos sociais educacionais e implica o reconhecimento da necessidade de superação de imaginários, representações sociais, discursos e práticas racistas na educação escolar. Representa também, um passo a mais no processo de "superação do racismo e de seus efeitos nefastos, seja na política educacional, seja na organização e no funcionamento da educação escolar" (GOMES, 2012, p. 8).

Nos apoiamos em Souza e Ayres (2016) ao defenderem que o Ensino de Ciências assim como qualquer área de conhecimento, tem papel basilar na promoção de relaçõesraciais/sociais entre os estudantes e professores e que a temática da diversidade étnicoracial não é ponderada no processo de aprendizagem na área de Ciências Naturais, assim, reconhecer a importância da educação das relações étnico-raciais no ensino de Ciências significa buscar a valorização da cultura negra e mudanças de atitudes, posturas e valores nas práticas educacionais deste campo, assim como o reconhecimento dos aspectos se torna basilar para um ensino mais apropriado e não estereotipado dos conhecimentos científicos (MATTHEWS, 1994).

No contexto Amazônico, a necessidade de rever o currículo que estar postos nas Escolas, onde comumente não se leva em consideração o contexto e o ambiente que determina instituição e sujeitos estão inseridos. Na perspectiva da abordagem do negro e da Cultura Africana, esses não percebem a essência da região e das influências dos conhecimentos, e que na qual são presenciados em diversas localidades da Região (BEZERRA NETO, 2008). No campo da Diversidade Étnico-racial, por exemplo, pouco se aborda no que tange a participação dos Africanos na pecuária principalmente na Ilha de Marajó e que a Capital Paraense também era porto de entrada de escravos africanos para o vale amazônico. Entretanto, esse currículo deve assim, perpassar por esses 
conhecimentos oriundos do Continente Africano, de maneira à transversalizar as disciplinas escolares da Educação Básica.

Essa necessidade na construção e na reformulação do currículo escolares, não parte apenas por causa da implementação da Lei N. 10.639/2003, mas por uma necessidade de construção de novos conhecimentos e saberes, recriando uma nova identidade (SILVA, 2007). Esse pertencimento colabora no processo de formação cidadã de todos os estudantes, recriando suas percepções sobre esse à Cultura Afro-brasileira e Africana.

Por essas e outras razões, que a discussão de currículo "é intimamente ligada a uma concepção dinâmica de cultura" (MAUÉS, 2006, p. 129). Essas considerações reafirmam da necessidade de ampliação conceitual do que é currículo, entendendo-o como parte da cultura e estendendo esse conceito para fora da sala de aula, e quando se fala em Amazônia deve-se pensar nas peculiaridades e heterogeneidade inerentes a esta região, as formações das identidades culturais da Amazônia, por exemplo, são complexas - saberes e valores e modos de vida da região são diversificados, analisando com as demais áreas.

Todas essas particularidades que envolvem os aspectos socioculturais da Região Amazônia, devem ser levadas em considerações pelos currículos escolares do Ensino Fundamental, esse currículo deve ser preenchido de conhecimentos e saberes de povos e comunidades de outros países e continentes, por exemplo, que influenciaram e influenciam nosso modo de entender, compreender e viver em sociedade. É preciso que as experiências educativas se pautam por um processo de educação dialógica que interrelacione sujeitos, saberes e intencionalidades, superando a predominância de uma educação bancária e assumindo um caráter multicultural (HAGE, 2006, p. 167).

O currículo no Ensino Fundamental deve ainda repensar a necessidade de reconhecimento das múltiplas etnias e culturas que existem dentro de uma sala de aula (CANEN, 2008), já que são cada vez mais comuns os discursos xenofóbicos, racistas e discriminatórios nas escolas brasileiras. Precisa-se, contudo, reforçar a necessidade de se questionar a função da educação e do currículo na formação de futuras gerações nos valores de apreciação a diversidade cultural da nossa sociedade. Mesmo porque, como explora Rodrigues (2012), o currículo também é inseparável da cultura, assim a 
elaboração de um currículo é um processo social, no qual convivem lado a lado os fatores lógicos, epistemológicos, intelectuais e determinantes sociais.

Nesses argumentos, esta produção tem como questionamento geral: Em que termos um processo formativo sobre a temática da História e Cultura Afrobrasileira e Africana, com os professores de Ciências atuantes no Ensino Fundamental, contribuiu para sua constituição como professor reflexivo na abordagem das Relações Étnico-raciais?

Para que o questionamento da pesquisa seja respondido passou-se a traçar o objetivo geral: Analisar em que termos um processo formativo sobre a temática da História e Cultura Afro-brasileira e Africana, para os professores de Ciências do Ensino Fundamental, contribuiu para sua constituição como professor reflexivo na abordagem das Relações Étnico-raciais. E dentre os objetivos específicos, destacamos: a) perceber se a temática da Cultura Afro-Brasileira e Africana no ensino de Ciências é proposta e trabalhada no ensino de Ciências e b) verificar as percepções dos docentes de Ciências no que diz respeito à implementação da Lei N. $10.639 / 2003$.

\section{ENCONTROS FORMATIVOS COM PROFESSORES DE CIÊNCIAS DO ENSINO FUNDAMENTAL}

Sendo um recorte da pesquisa de dissertação de mestrado ${ }^{1}$, esta produção se baseia na pesquisa qualitativa (GOLDENBERG, 2004) de caráter pesquisa ação (THIOLLENT, 1986), apoiada nas concepções de Clandinin e Connely (2011), sobre os fenômenos da pesquisa narrativa. Após aos levantamentos da literatura especializada (COELHO, 2009, GOMES, 2012, SILVA, 2007) que consubstanciaram as análises desta investigação, foi realizada algumas visitas na Escola Municipal de Ensino Fundamental Ribeirão das Neves

\footnotetext{
${ }^{1}$ OLIVEIRA JÚNIOR, Waldemar Borges de. A educação das relações étnico-raciais: uma experiência formativa com professores de Ciências do Ensino Fundamental. 2018, 186f. Dissertação (Mestrado em Docência em Educação em Ciências e Matemáticas), Programa de Pós-graduação em Docência em Educação em Ciências e Matemáticas, Universidade Federal do Pará, Belém, 2018.
} 
(EMEFRN) que fica localizado no Município de Oeiras do Pará - PA, a qual foram realizados diálogos iniciais com os diretores, coordenadores e os professores de Ciências atuantes em turmas do $6^{\circ}$ ao $9^{\circ}$ ano do Ensino Fundamental. A escolha da instituição, ocorreu pela ocorrência que um dos autores desta pesquisa, atuava como docente da instituição e identificou a importância de bases formativas sobre a temática das relações raciais para os demais professores de Ciências.

Para alcançar o objetivo central da pesquisa, foram realizados quatro encontros formativos $^{2}$ (GARCIA, 2013) e aplicação de um questionário3 a respeito da temática das relações étnico-raciais e ensino de Ciências. Dentre alguns objetivos dos encontros formativo, foi de proporcionar aos professores de Ciências da EMEFRN bases epistemológicas para conhecer a legislação vigentes e seus entrelaces nas aulas de Ciências no Ensino Fundamental.

Como instrumentos investigativos da pesquisa, optamos pela utilização de registro de áudio e por meio de fotografias e para o tratamento do material empírico, se baseou na Análise Textual Discursiva (MORAES; GALIAZZI, 2011). Além disso, após essa os diálogos iniciais, foi agendado com os professores de Ciências, a entrega do planejamento dos quatros encontros formativos e os demais materiais que seriam

\footnotetext{
${ }^{2}$ Através dos diálogos previamente agendada e marcada com os professores de Ciências, ficou decidido que quatro professores de Ciências da EMEFRN poderiam participar dos encontros formativos (no total a escola tem seis docentes da área), e que cada momento teria duração de $3 \mathrm{~h}$, as quais foram realizadas pela parte da manhã (ogh às $12 \mathrm{~h}$ ) e à tarde (14h às 17h).

3 Indagação 1: Como você se diz professor? Como se deu sua formação inicial?; Indagação 2: Você já ouvia falar sobre a Lei ${ }^{0}$ 10.639/2003? Se sim, sabe do que se trata?; Indagação 3: Você sabe ou já ouviu falar, quais foram os principais acontecimentos que ocasionaram o surgimento da Lei N. 10.639/2003?; Indagação 4: Você sabe quais são os objetivos centrais da implementação da temática das relações étnicoraciais nos currículos escolares? Justifique sua resposta; Indagação 5: Você acredita que a atuação política dos negros brasileiros foi importante para o surgimento dessa legislação? Justifique; Indagação 6: Durante sua formação inicial houve alguma disciplina na qual abordava a História da Cultura AfroBrasileira e Africana?; Indagação 7: Após sua atuação na Escola Municipal de Ensino Fundamental Ribeirão das Neves, você já participou de algum curso, minicurso ou palestra sobre a temática da História e Cultura Afro-Brasileira e Africana? Justifique sua resposta; Indagação 8: Hoje, antes de ministrar suas aulas de Ciências no Ensino Fundamental, você a planeja com a finalidade também de implementar essa legislação vigente? Justifique sua resposta
} 
utilizados nos momentos formativos, a saber: o primeiro encontro formativo se caracterizou sobretudo na discussão sobre o Ensino de Ciências na EMEFRN e a necessidade de sua renovação. O segundo encontro teve como objetivo, proporcionar aos docentes o conhecimento da Lei N. 10.639/2003 e sua importância no combate a casos de discriminação e racismo nas escolas, o terceiro encontro tinha como finalidade, oportunizar aos professores, conteúdos e assuntos da área de Ciências Naturais, na qual podem serem correlacionados sobre a História da Cultura Afro-brasileira e Africana, e no quarto encontro decidiu-se elaborar em parcerias com os professores, planos de aulas, na qual o professor poderia trazer a temática da História da África para as suas aulas, assim como suas reflexões sobre o processo formativo realizado. Existem aspectos relativos aos quatro professores que participaram da formação, a saber: I) Para preservar a identidade dos participantes, realizou-se a opção de atribuir nomes fictícios para denominá-los, os mesmos estão identificados com nomes de bairros do Município de Oeiras do Pará (escolhidos pelos próprios professores)

\subsection{A trajetória formativa sobre relações raciais e ensino de ciências}

Ao tratar dos relatos dos professores que participaram dos encontros formativos, encontramos em sua voz, suas histórias de vida, seu protagonismo narrador, algo que sempre buscamos registrar durante a construção da pesquisa, registrando suas particularidades e singularidade de suas histórias enquanto professor da Instituição.

Ressaltamos as ideias de Gonçalves (2011) que narrar nossas histórias, é uma maneira de nos dá uma identidade. Mas Nóvoa (2013) considera mais adequado falar em processo identitário, ressaltando a dinâmica que caracteriza a maneira como cada um se sente e se diz professor. Para o autor, esse processo apresenta complexidade constituída nos entrelaçados em que cada um se apropria dos sentidos atribuídos às histórias de suas vidas pessoais e profissionais.

Podemos dizer que nesses entrelaçados de sentidos e significados encontrados nas narrativas de cada professor de Ciências, possibilitaram na qual eu tentar-se descrever 
suas percepções, conhecimentos e anseios referidos aos questionamentos deste estudo, e assim, possibilitar uma amplitude maior sobre as análises dos quatro encontros formativos.

\subsubsection{Primeiro Encontro Formativo}

Este momento é relativo às manifestações dos percursos de formação dos professores de Ciências, das suas percepções sobre a temática racial (obtidas através do questionário) e sobre os diálogos oriundos do primeiro encontro formativo (discussão epistemológica sobre o ensino de Ciências)

No primeiro encontro com os professores de Ciências, suas manifestações de seus percursos formativos4, foram algo que de início ambicionamos em saber, com o propósito de conhecê-los e saber sobre sua formação. No momento dos diálogos com os professores, observou-se as percepções dos mesmos que o Ensino de Ciências vem passando por uma “crise sendo necessária sua renovação”. Liberdade diz:

Existe sim a crise no ensino de Ciências e eu acredito que isso ocorra principalmente da forma como se deu nossa formação inicial e pela falta de estrutura das escolas, não pelo fato do plano de aula a ser seguido. Aqui por exemplo não temos um laboratório de Ciências. Isso faz com que optamos por buscar materiais alternativos, mesmo que a gente professor de Ciências conseguimos trabalhar com esses materiais mais simples, acredito que ainda vai ter essa deficiência na formação dos nossos alunos, mesmo porque eu vejo esta disciplina como não simples e sim complexa, que deve ser palpável, precisando também de outros materiais (LIBERDADE).

A voz do/a professor/a expressa sua opinião sobre a crise no Ensino de Ciências e a necessidade de renovação. Fourez (20003) e Cachapuz et al (2005) já afirmam que devem haver mudanças e modificações referentes, a maneira que este ensino vem sendo

\footnotetext{
${ }^{4}$ LIBERDADE: Estudou seu curso de Licenciatura em Ciências Naturais no próprio Município de Oeiras, no regime conhecido como intervalar. SANTA MARIA: Também estudou em Oeiras do Pará, no regime intensivo. Disse que não era sua primeira opção de início, mas como não tinha condição de naquele momento estudar na capital do Estado, prestou vestibular para a sua localidade, passou e se formou anos depois. MANOEL TAVARES: Manoel Tavares também foi um docente que se formou pelo processo de interiorização das Universidades, no caso novamente em Oeiras e MARITUBA: Se formou longe de Oeiras do Pará, na época o Município não tinha Universidade Pública e nem privada, e viu-se em recorrer a outra localidade para ter sua formação em Ciências Biológicas.
} 
proposto dentro do ambiente escolar, além de transformações de cunho didático por parte dos professores. Proporcionar atividades distintas da aula puramente tecnicista auxilia na constituição de um aluno crítico e mais participativo nestas aulas, algo que o professor. Proporcionar atividades distintas da aula puramente tecnicista auxilia na constituição de um aluno crítico e mais participativo nestas aulas, algo que o professor Santa Maria já teria percebido ao dizer "tem que mudar e temos que buscar esse ensino de Ciências diferente. Buscar algo simples, para renovar e melhorar esse processo de aprendizagem dos alunos”.

Além disso, é evidente que uma escola que proporcione estruturas adequadas para ocorrer suas atividades referente a disciplina, ajuda no processo de aprendizagem dos alunos, mas Souza (2011) alerta que para ocorrer uma aula mais atrativa de Ciências, não é preciso laboratório equipado com materiais sofisticados, o professor pode se reinventar e levar para suas salas de aulas, materiais simples e de baixo custo, que podem proporcionar o debate de conceitos científicos e sociais para a disciplina.

No decorrer dos diálogos, alcance a formação inicial de professores, está também mencionada, ao serem indagados na questão 6 do questionário, se durante a etapa inicial da sua constituição como professor, houve alguma disciplina na qual abordava a História da Cultura Afro-Brasileira e Africana, eles relataram:

Não. Em nenhum momento durante meu curso de Ciências Naturais ocorreu alguma disciplina sobre a temática (MANOEL TAVARES)

Não. Não houve nenhuma disciplina que abordava a História da Cultura Afrobrasileira e Africana (LIBERDADE)

Não. Durante sete semestres de curso, não houve qualquer disciplina (SANTA MARIA).

Não. Não vimos nada sobre a temática no curso de Ciências (MARITUBA)

Mesmo atuando na EMEFRN, a realidade não foge desse padrão, nunca foi proporcionado a eles algum curso, minicurso e palestra sobre a temática da História e Cultura Afro-Brasileira e Africana, dado esse também referente a indagação 7. "Não. Gostaria de ter participado de alguma formação sobre a temática na escola (MANOEL TAVARES)"; "Não. Tenho certeza que seria ótimo para nossa formação (MARITUBA)". 
As narrativas dos professores evidenciam que durante seu curso de graduação sequer tiveram disciplina sobre a História da África na grade curricular dos seus cursos, evidenciando que uma formação inicial mais consistente é preciso no enfrentamento de temas urgentes e necessários para entender a formação do Brasil. Igualmente, as formações contínuas nesses casos de ausência na formação inicial surgem como primordial, visando que todo as Instituições devem cumprir com todas as legislações educacionais vigentes (CRUZ, 2017).

Quando o professor Manoel Tavares anuncia que "Gostaria de ter participado de alguma formação sobre a temática na escola”, ele recorda um momento de insatisfação na sua constituição enquanto docente sobre a temática. Nesses episódios, o assessoramento das Universidades e Secretarias de Educação podem ter papel efetivo no aumento de bases formativas sobre a temática das relações raciais, mesmo que a realidade mostre ao contrário, por quê a formação docente é um processo que se constrói no decurso da vida profissional e que vai além de uma formação formal (MATOS, 2015). A figura 1 registra o processo formativo do primeiro encontro com professores de Ciências.

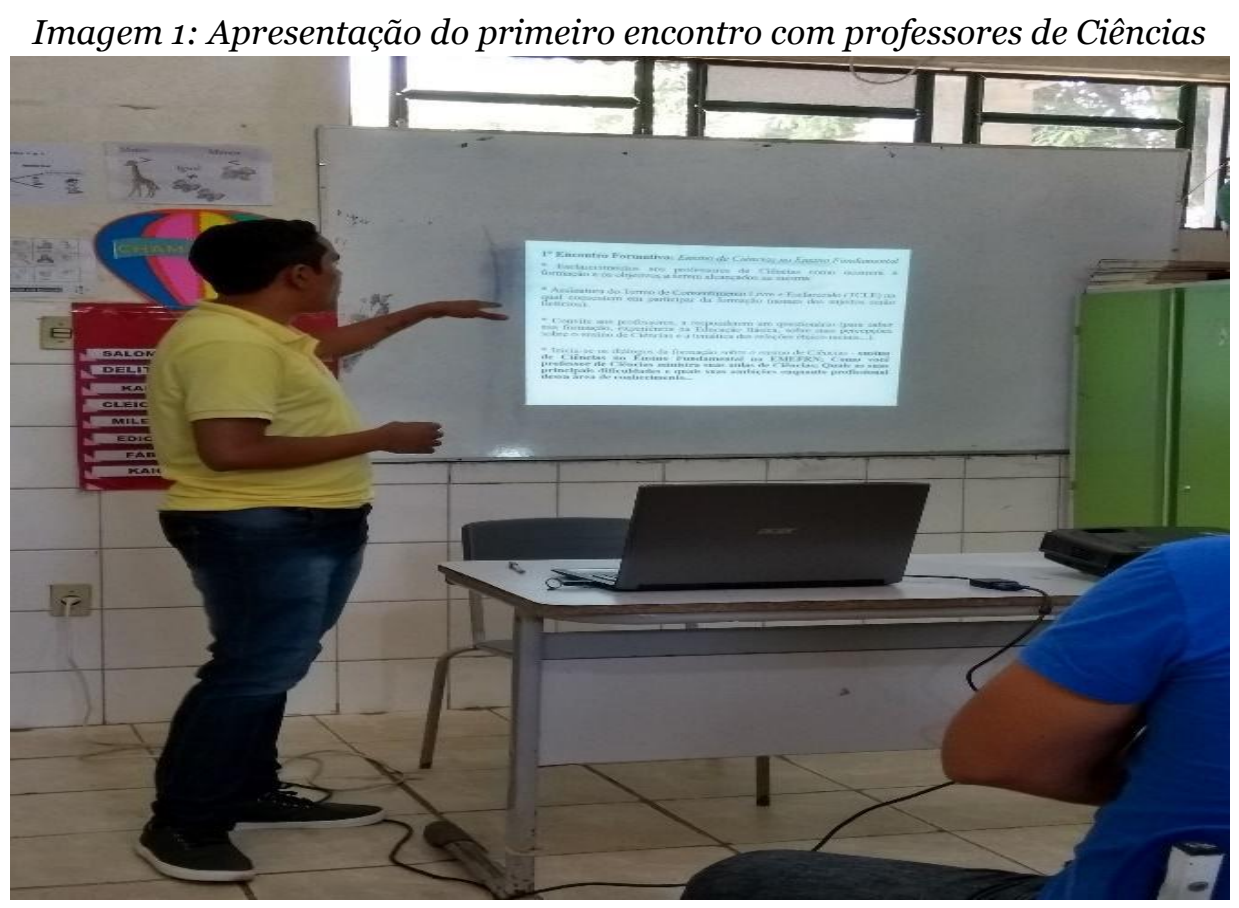

Fonte: Acervo dos autores 


\subsubsection{Segundo Encontro Formativo}

No segundo encontro formativo com os professores de Ciências, priorizou-se em identificar se os professores presentes, saberiam quais os principais objetivos da implementação da Lei N. 10.639/2003; suas percepções sobre a temática; se já tinham escutado falar sobre a legislação; se a pesquisa era o primeiro contato com a temática das relações étnico-raciais e etc.

Na segunda pergunta do questionário os professores teriam que responder se eles já tinham ouvido falar sobre a Lei N. 10.639/2003? Caso positivo, se saberiam do que se tratava?, os professores Liberdade, Santa Maria, Marituba e Manoel Tavares foram sensatos ao responderam que não conheciam a temática das relações étnicoraciais, e que não imaginavam do que se tratavam (os quatros professores não estavam presente na primeira etapa da pesquisa), apenas Marituba relatou que saberia mais ou menos e que achava que tinha relação sobre a questão racial na educação brasileira.

Fica manifesto que a Lei N. 10. 639/2003 ainda é um objeto desconhecido por parte desses docentes da EMEFRN, na visão do professor Marituba, fica claro as percepções ainda restritas sobre a legislação vigente. Esse resultado impressiona, pois já são vários anos que a Lei Federal está em vigor, e ainda se encontra docentes, que desconhece a legislação de uma temática imprescindível nas escolas.

Iniciando o segundo encontro formativo, primeiramente nos concentramos em articular com os sujeitos, sobre alguns movimentos sociais e os Núcleos de Estudos Afrobrasileiros e suas influências para o surgimento de políticas de ações afirmativas, aspirando no combate às desigualdades sociais que o Brasil vinha/vêm enfrentando. A partir desse momento, a formação se deu sobre o surgimento da Lei N. 10.639/2003, salientando sobre o seu significado e seus principais objetivos e importância para a educação básica brasileira. 
No decorrer desta apresentação, exibiu-se dois vídeos 5 que traz ponto de vistas de professores sobre a temática das relações étnico-raciais. Após a apresentação, os quatro professores comentaram:

\begin{abstract}
Nossa o esse vídeo mostrou mesmo, o quanto nossa formação inicial não foi o suficiente para saber enfrentar e conhecimento dessa temática importante para a da educação básica, e olha que nossa formação é recente, imagina os professores mais antigos. Fiquei surpreso em ser uma temática urgente e que a gente desconhece e ainda não ver aqui na Escola (LIBERDADE)

Nossa quinze anos, e não sabíamos dessa legislação, algo tão emergente para a educação. Como o vídeo falou aí, precisa-se de formação para os professores, como é o nosso caso também (SANTA MARIA).

Eu tive acesso há pouco tempo à temática, mas imaginava que era somente necessário no ensino de História. Não sabia que no ensino de Ciências era preciso (MARITUBA)

O vídeo fala sobre essa importância da temática, e lembrei vários casos que passa na mídia, e como ela consegue alienar ainda mais nós brasileiros sobre os questionamentos da África [...] (MANOEL TAVARES)
\end{abstract}

As descrições feitas pelos professores, após acompanhar os vídeos, visibilizam seus espantos em relação à temática, que foi promulgada em dois mil e três, relevando o desconhecimento da temática, até mesmo na própria EMEFRN como enaltece Liberdade - "Fiquei surpreso em ser uma temática urgente e que a gente desconhece e ainda não ver aqui na Escola" - Santa Maria também seguindo o mesmo entendimento se refere que mesmo passado quinze anos da legislação, não sabia sobre o tema, nunca teve contato sobre, algo que é tão urgente para a educação".

Coelho (2010) e Gomes (2011), evidencia que em muitas escolas brasileiras a Lei 10.639/2003 de fato não é implementada, motivos esses que vai de despreparo dos professores sobre o assunto, chegando à falta de interesse das escolas em levar adiante a temática para os diálogos com os alunos, geralmente voltando-se apenas para comemoração do dia 20 de novembro (dia da Consciência Negra), não refletindo sobre o real sentido desta comemoração. Além de tudo, a temática da História da África não pode ser somente vista como uma obrigação na educação básica, a extensão que a legislação

5 Vídeos disponíveis em: https://www.youtube.com/watch?v=Ula2K-MzysU e https://www.youtube.com/watch?v=q_Y_mCFvA-4\&t=99s . Acesso em: 29 de agosto de 2008. 
pode alcançar na formação de docentes, podem ser um ponto efetivo, para estimular os professores e aqueles que estão em formação, na discussão dos aspectos centrais da temática, pois assim, pode gerar no professor a segurança para argumentar o problema, já que é uma lei que o auxilia neste processo. O professor Manoel Tavares, cita sobre o referido acima - "É meu primeiro contato professor. Nem durante as formações continuadas que tive a oportunidade de participar, não me proporcionou conhecer essa lei”, assim a formação dos professores não lhes asseguram a abordar assuntos mínimos sobre a Lei nas escolas, pois não foram lhe proporcionado formação inicial e nem continuada sobre a valorização da diversidade no seu âmbito profissional. A imagem 2 demonstra o início do segundo momento do processo formativo com os professores de Ciências.

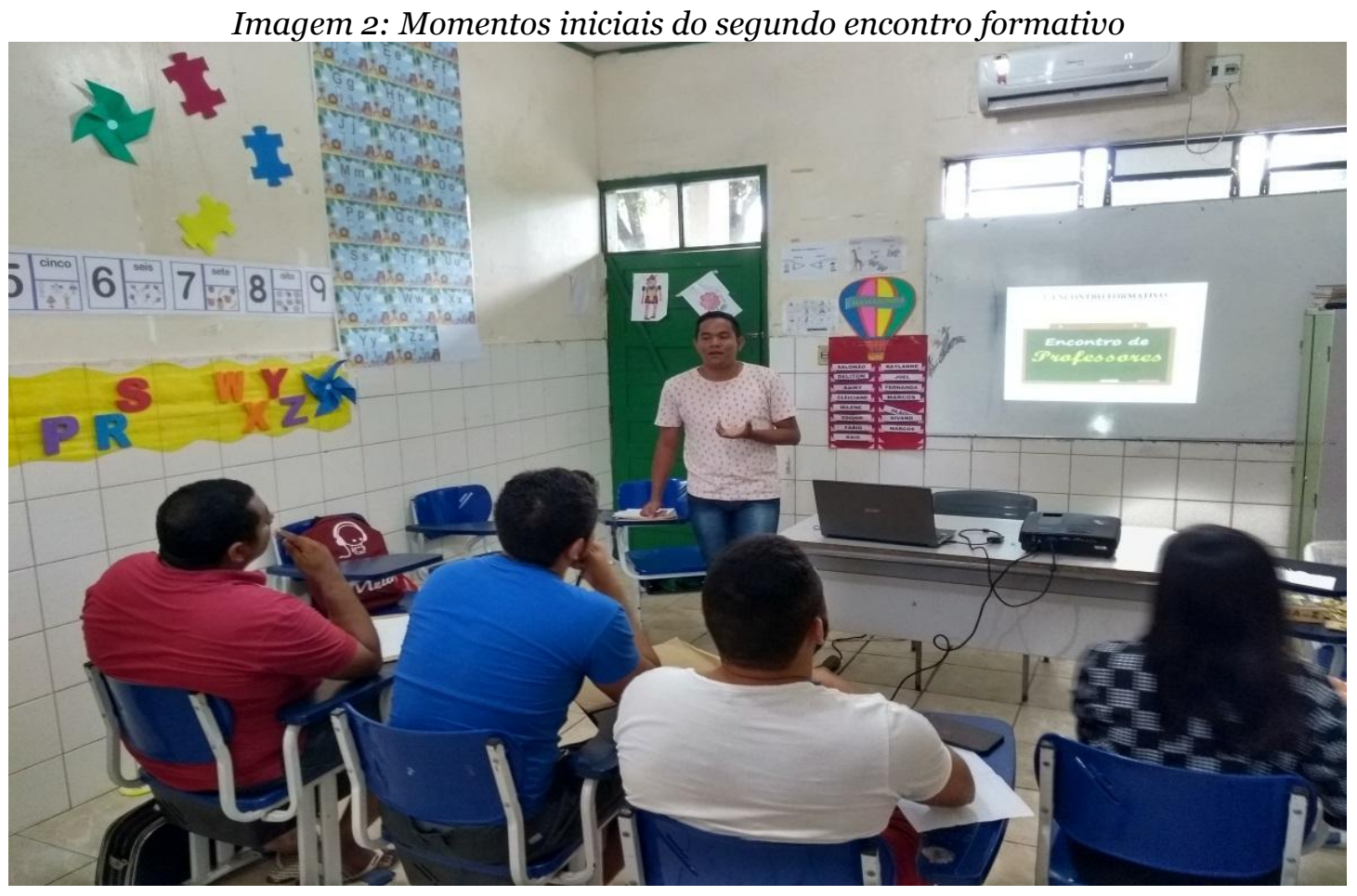

Fonte: Acervo do autor

\subsubsection{Terceiro Encontro Formativo}


Esta etapa é relativa às algumas manifestações dos professores de Ciências sobre o terceiro encontro formativo e sobre suas percepções sobre a temática da História e Cultura Afro-brasileira e Africana no ensino de Ciências (aplicação do questionário).

Chegando ao terceiro encontro formativo com os docentes de Ciências da EMEFRN, priorizou-se em conversar com os professores sobre a temática das relações étnico-raciais no ensino de Ciências; dialogando sobre assuntos/conteúdos desta área de conhecimento que podem ser trabalhados com os alunos do Ensino Fundamental.

Antes de iniciar as discussões e a apresentação sobre os tópicos principais deste encontro, pedi para os professores relatassem algumas indagações sobre relações raciais e referente à pergunta se é possível ser trabalhada e discutida a temática da História e Cultura Afro-brasileira e Africana no ensino de Ciências, com os alunos do Ensino Fundamental, obteve-se:

Acredito que sim, esse momento está sendo oportuno para tentar perceber essa relação. A cada encontro percebo que a legislação é ampla e possibilita esse olhar para nós professores de Ciências (SANTA MARIA).

Sim, mas a meu ver a falta de uma formação para nós professores de Ciências, torna-se um obstáculo para tentar trabalhar a temática durante as aulas. Que a meu ver é o principal problema (MARITUBA)

Eu na verdade nunca pensei em implementar a lei, principalmente por que eu não tive formação. Então pelo desconhecimento da lei, e também pelo desinteresse nosso de tentar implementar em uma aula de Ciências dificulta esse processo. Mas sem dúvida, acredito que essa relação é possível, e que espero aprender um pouco agora nesse andamento desse terceiro encontro. (LIBERDADE)

Por meio do que os professores de Ciências apontaram, eles acreditam que a temática na qual a Lei N. 10.639/2003 se refere, pode ser sim proposta no ensino de Ciências, contudo, enfatiza novamente que a formação que lhe foi proposta não lhe garantiu esse suporte. Isso fica claro na fala do professor Santa Maria ao dizer "torna-se um obstáculo para tentar trabalhar a temática durante as aulas. Que a meu ver é o principal problema”, o desinteresse por parte de alguns docentes também fica explícito, contudo, vale lembrar que a autonomia em buscar novo saberes, também tem que partir por parte do corpo docente da Instituição. 
Essas informações nos fizeram lembrar Coelho, Coelho e Nascimento (2012) ao realizarem uma pesquisa, em algumas escolas na Região Norte, ponderam constatar algo, que está totalmente direcionado com as vozes dos professores - a necessidade de formação - sem suporte formativo, torna-se ainda mais complexo a abordagem sobre a cultura negra nos currículos escolas e nas práticas pedagógicas dos professores. Sobre o ensino de Ciências, possibilitar a temática na educação básica nas formações, pode desencadear uma educação que respeita a abrangência histórica e cultural de uma sociedade tão complexa como a brasileira, garantindo o reconhecimento da identidade, história e cultura dos afro-brasileiros e a valorização das raízes africanas na nossa sociedade (VERRANGIA, SILVA 2010).

Se os suportes formativos não forem propostos nas formações iniciais e nas continuadas de professores de Ciências, é notório as dificuldades que vão enfrentar ao tentarem implementar a legislação, eles se pronunciaram sobre essas dificuldades:

Sim, tenho dificuldades, pelo fato novamente de nunca ter ouvido falar nessa legislação na Faculdade e muito menos na formação continuada que às vezes é proporcionada para nós professores da Escola (SANTA MARIA)

Tenho dificuldades sim de tentar implementar a lei nas minhas aulas, eu não conhecia a lei até esses encontros, assim não implementava ela nas minhas aulas de Ciências (LIBERDADE)

Acredito que dificuldades vamos sempre enfrentar, primeiro pela formação que nos foi dado e segundo pela resistência que vamos acabar enfrentando aqui na escola (MARITUBA)

Essas dificuldades já eram perceptíveis quando eles responderam à pergunta oito do questionário - se antes deles de ministrarem suas aulas de Ciências, chegavam a planejar ela, com a finalidade de implementar a Lei N. 10.639/2003. Liberdade, Santa Maria, Marituba e Manoel Tavares, responderam da mesma forma, que não planejam suas aulas, ou porque não conhecia a legislação ou por que não conseguia ver a relação da temática com os conteúdos de Ciências.

Esses dados obtidos da formação nos fazem refletir do papel da legislação em torno do processo de ensino e aprendizagem da disciplina de Ciências, e na formação de 
professores reflexivos (ZEICHNER 1993). Os obstáculos que tentar realizar aulas de Ciências, com o intuito de correlacionadas na disciplina de Ciências da Natureza, é prejudicada pela formação que aquele professor recebe, ou seja, para que o professor de Ciências possa “educar" relações étnico-raciais positivas, eles precisam estar "habilitados" para fazer abordagem com essa conjuntura (VERRANGIA, 2009). A ilustração abaixo evidencia, o momento inicial do terceiro encontro.

Depois de apresentar sugestões de como planejar aulas de Ciências no Ensino Fundamental relacionando-as com conteúdos mínimos sobre a História da África, os professores perceberam o quanto a conexão com a temática é possível e essencial na educação básica. Após esses momentos eles ponderaram:

É incrível professor como a relação é possível mesmo. Esse momento está sendo muito importante para perceber essa conexão com a nossa área de ensino (MARITUBA, 2018).

Nunca tinha parado para pensar que era possível essa relação com Ciências. Pensei que era somente preciso na disciplina de História. (SANTA MARIA, 2018).

Até antes estava me perguntando como essa temática era possível com nossa área. A partir do nosso terceiro encontro pude perceber isso. Muito bom mesmo (LIBERDADE, 2018).

E não é que a relação com nossa área é possível mês, e com assuntos que somos acostumados a trabalhar com nossos alunos, evolução, genética. (MANOEL TAVARES, 2018).

Os relatos dos nos conduz a dizer, o quanto ficaram admirados com os possíveis entrelace no ensino de Ciências, mesmo crendo que a possibilidade somente ficaria a cargo da disciplina de História, como mencionado pelo professor Santa Maria "Pensei que era somente preciso na disciplina de História”. Paula e Guimarães (2014) articulam que muitos docentes da educação básica, ainda idealizam que a temática da História e Cultura Africana se torna necessária somente na disciplina de História, deixando como plano secundário as demais áreas de conhecimento. Porém, Verrangia (2010) destaca que dentre as necessidades de enfoque na disciplina de Ciências está a necessidade de superar a ideia de neutralidade política das Ciências Naturais e o compromisso de abordar de forma mais adequada a diversidade cultural, no contexto de uma educação para uma cidadania crítica, assim, trazer a abordagem vai corroborar para ampliar as percepções de alunos sobre a 
História da Ciência, desmitificando os discursos eurocêntricos dos currículos escolares e das salas de aula.

Imagem 3: Conversas iniciais no terceiro encontro formativo

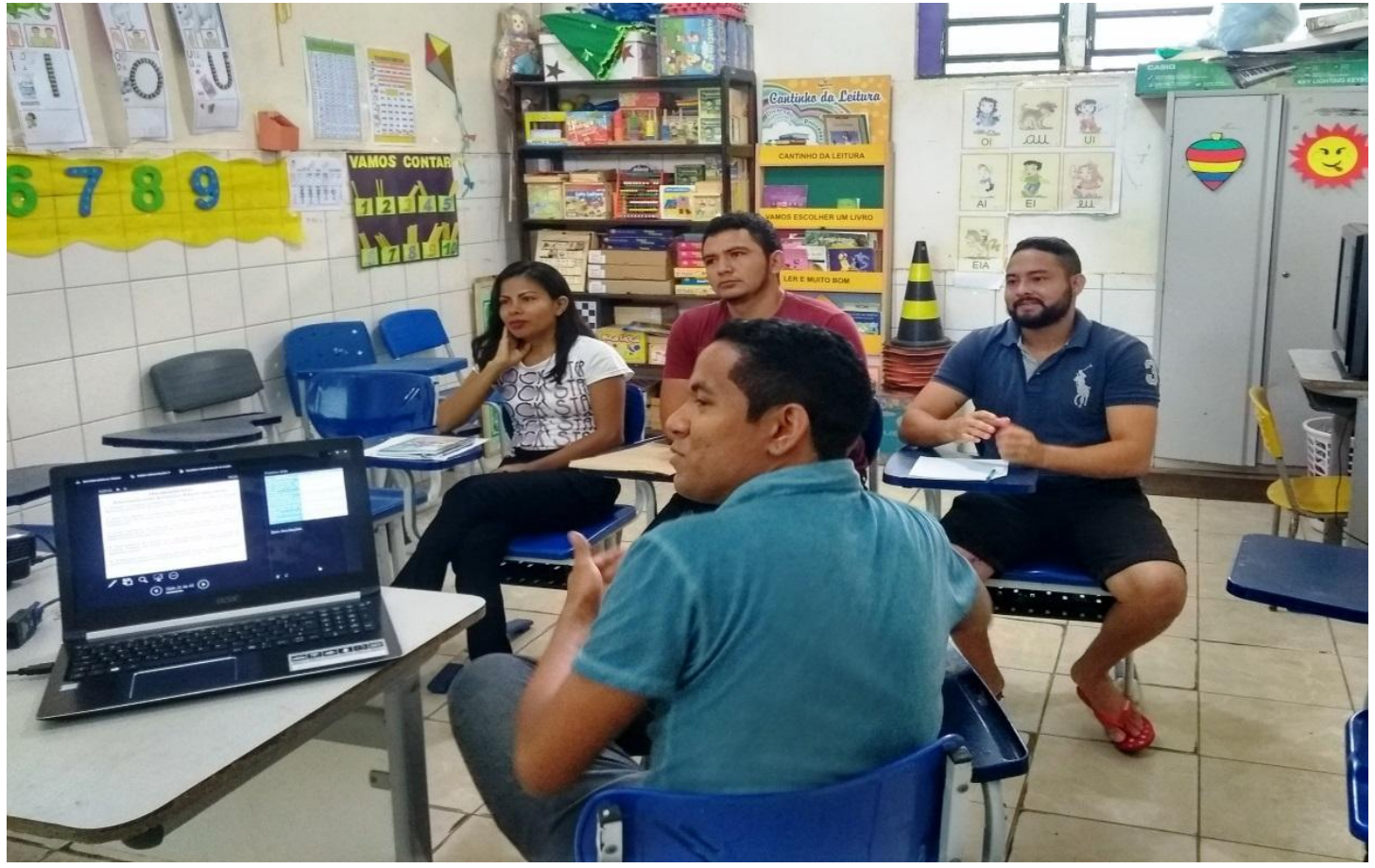

Fonte: Acervo do autor

2.1.4 $\mathrm{O}$ quarto encontro formativo

O quarto e último encontro da formação realizado com os professores de Ciências tinha como objetivo fundamental, iniciar a proposta do produto da pesquisa de dissertação - um miniaula de Ciências relacionado sobre os animais do continente africano ${ }^{6}$. Mas para a construção de determinada aula, precisa-se de um planejamento consubstanciado, partindo desse pressuposto, o eixo norteador do quarto encontro foi construir planos de aulas que fazem a correlação da temática das relações étnico-raciais com o ensino de Ciências, baseando-se nos eixos temáticos da Base Nacional Comum Curricular - BNCC (2018). Essas produções foram elaboradas em parcerias com todos os

\footnotetext{
${ }^{6}$ Produto didático da dissertação disponível em: https://www.youtube.com/watch?v=2zw5yPG4voY\&t=3s
} 
sujeitos da formação. No total foram construídos três planos de aula7, que auxiliaram na construção do produto. A imagem abaixo exibe o momento do último encontro formativo.

\section{Imagem 4: Iniciando o quarto encontro formativo}

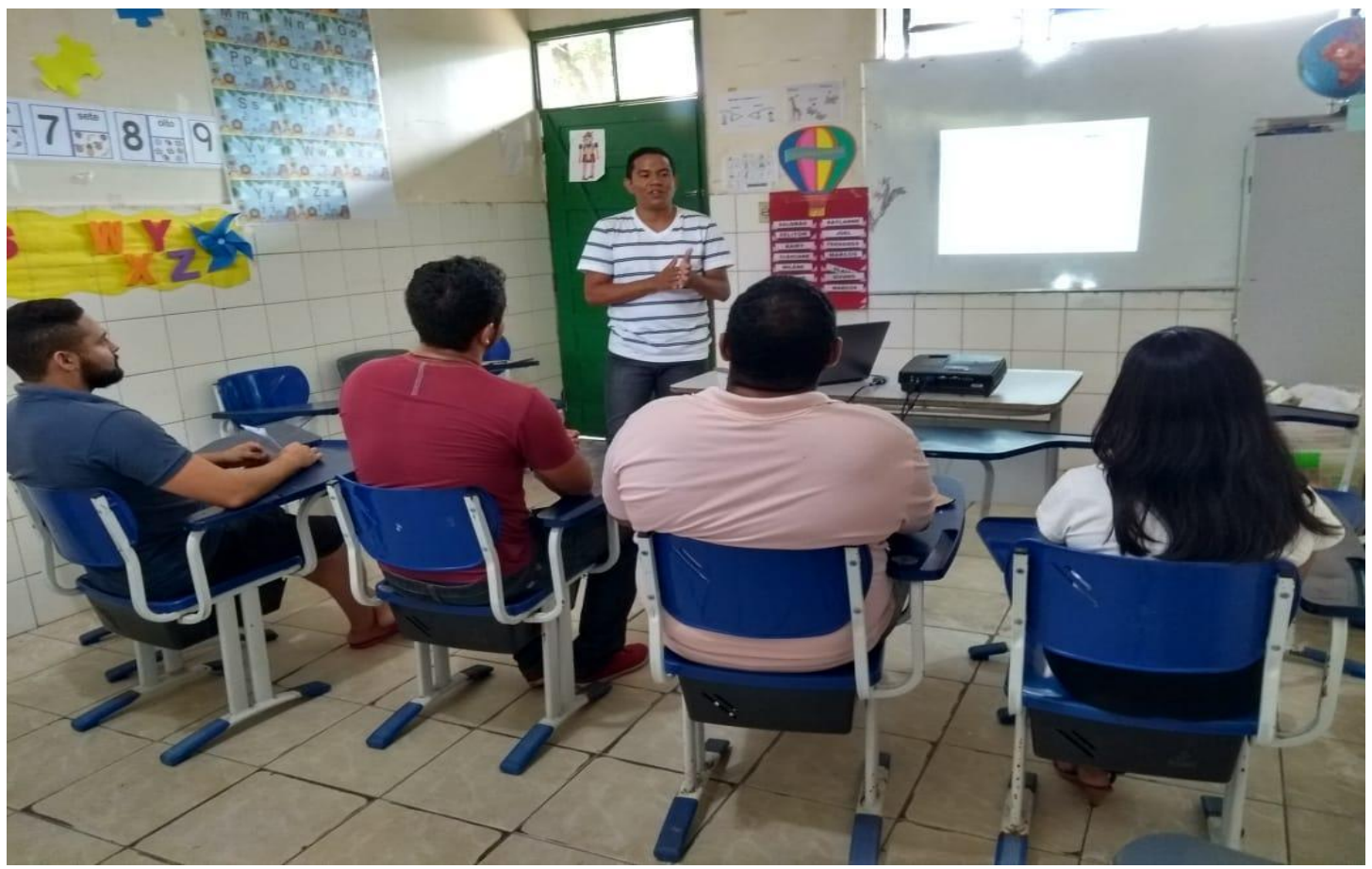

Fonte: Acervo do autor

Terminando as elucidações da construção do produto, partiu-se para iniciá-lo, para isso, foram construídos pelos professores que participaram da formação e inclusive eu, três planos de aula para a disciplina de Ciências, na qual as mesmas, direcionam para a História da África. Foi uma construção em parcerias, ouvindo ideias e pensamentos de todos os professores. Para esses planejamentos, os encontros anteriores teriam papéis primordiais para os docentes conhecerem a temática, assim como a possível e necessária relação com disciplina de Ciências da Natureza. Além disso, conhecer brevemente os aspectos e os eixos temáticos da BNCC para a referida disciplina, também se tornaram vital na elaboração desses planejamentos para o Ensino Fundamental.

7 Os eixos as quais os planos de aula se balizam, relaciona-se a Vida e Evolução (turmas do $6^{\circ}, 7^{\circ}$ e $8^{\circ}$ ano do Ensino Fundamental). Ver discussão em: Oliveira Júnior (2018). 
Para finalizar o percurso de troca de saberes, conhecimentos e de experiência profissionais, convidamos os quatros professores, para relatarem sobre suas experiências no processo de formação realizado, expondo como analisam os mesmos e se foi essencial na sua constituição enquanto professor de Ciências da EMEFRN. Os docentes Santa Maria, Marituba e Manoel Tavares narraram:

A minha análise sobre esses momentos, foi muito proveitosa já que antes desses encontros, a gente só ouvia falar, ou conhecia a sim... muito relacionado as aparências. Sobre o que a lei trabalha em si não! Foi sim essencial e muito importante esse momento e agradeço a oportunidade também professora. Além disso, observo que... essa legislação veio a abrir novos horizontes de como deve ser trabalhado essa temática da relações étnico-raciais nas aulas de Ciências Naturais. Vou tentar e gostaria muito de trabalhar na sala de aula, com os meus alunos [...] (MANOEL TAVARES)

Esses encontros foram ótimos para a minha formação enquanto professor, percebi que a temática, é uma ótima abordagem para ser trabalhado, também no ensino de Ciências. É uma temática boa, tem muitos assuntos de ciências que ela pode ser incluída, e trabalhada dentro da disciplina de Ciências, e que vai ajudar na formação social dos nossos alunos ajudando a essas questões étnico-racial e do racismo e de qualquer forma de preconceito, através da separação das raças que é muito grande no Brasil (MARITUBA)

Foram encontros bons, porque como discutimos nos encontros anteriores, na nossa formação inicial, não tivemos conhecimento da lei, tanto eu como os colegas, e ele foi sim essencial, nessa minha constituição como professor da educação básica, porque me ajudou a ter uma visão mais diferente, ou seja, que eu possa trazer esses assuntos para a sala de aula. Com esses encontros, acabei de ver que dá para trazer a temática no ensino de Ciências, antes eu não conseguia. Mas a partir desse momento que teve esses encontros aqui e que tivemos conhecimento da lei, e como podemos usar o conteúdo, na disciplina de Ciências. E sim agora vou tentar usar nas minhas aulas (SANTA MARIA)

As palavras dos professores mostram a significância dos encontros formativos realizados no tocante a temática das relações raciais no ensino de Ciências. Em suas narrativas, identifica-se que os momentos contribuiu no conhecimento da temática da História e Cultura Afro-brasileira e Africana e observar que esta pode se relacionar dentro dos âmbitos escolares na área de Ciências da Natureza, como exposta por Santa Maria “Com esses encontros, acabei de ver que dá para trazer a temática no ensino de Ciências, antes eu não conseguia. Ficava pensando com o colega quando saímos daqui, como vamos fazer isso é mais para a área de literatura, história”. 
Entende-se que a formação que foi oportunizada aos professores, corroborou na sua constituição como professor de Ciências e como professor reflexivo, ao nosso entender, o processo formativo realizado com os professores da EMEFRN foi válido, à medida que trazer a abordagem das relações étnico-raciais na escola básica e para o ensino de Ciências, ajuda no processo de humanização (VERRANGIA; SILVA, 2010) e na melhoria de escolarização para todos, além de possibilitar construções positivas de identidades (SILVA, 2007) também nas aulas de Ciências.

\section{CONSIDERAÇÕES FINAIS}

Esta produção teve como proposta central, a realização de encontros formativos assumido coletivamente por quatro professores de Ciências da EMEFRN. A intencionalidade no processo, era propor e dialogar com os docentes, sobre o ensino de Ciências, a temática das relações étnico-raciais e as' possibilidades de entrelace nas aulas de Ciências do Ensino Fundamental, todos estes se pautaram em referências teóricos que nos auxiliaram para aprimorar essa etapa da formação.

Os professores Santa Maria, Liberdade, Marituba e Manoel Tavares, no primeiro encontro, apontaram principalmente suas principais dificuldades e pretensões no ensino de Ciências, percebendo-se por meio dos relatos, que eles acreditam que a crise no ensino de Ciências ocorre sobretudo, pela carência de uma formação inicial consistente e pela falta de estruturas das escolas, mencionando que as ausências de materiais e de um laboratório de Ciências, dificultam o processo de aprendizagem dos alunos na instituição. Além disso, para os professores, suas formações mostraram um ensino de Ciências diferente da realidade da sala de aula e dos alunos do Ensino Fundamental, ou seja, os docentes passaram assumir e a compreender as suas limitações relacionadas a formação inicial.

Por meio do segundo encontro, observou-se que os professores desconheciam a temática das relações étnico-raciais, ficando evidente que a Lei N. 10. 639/2003 era um objeto desconhecido no ensino de Ciências na EMEFRN. Consideramos que a formação 
realizada com os professores, apesar de não ter solucionado os problemas da educação em Ciências na escola, surgiu como um arcabouço de ação para iniciar as mudanças didáticos e pedagógicos no processo de aprendizagem da área. Pesquisas educacionais retratam que o desafio é amplo para expandir os conhecimentos sobre a História da África nos currículos escolares, mas necessário, à medida que visa os princípios básicos da educação básica brasileira, que é a formação para a cidadania.

Após terem o contato com alguns questionamentos que envolviam a temática, os professores, perceberem a urgência em trabalhar com seus alunos os conteúdos mínimos sobre as relações raciais, revelando que esta propicia conhecimentos epistemológicos para o enfrentamento de casos de preconceitos e discriminação na escola básica. Concebemos ainda, que em se falando em Educação em Ciências, torna-se essencial dialogar com o setor educacional, pois a escola tem papel preponderante por possibilitar acesso aos registros culturais diversos.

A pesquisa mostrou ainda, que os docentes não compreendiam em como fazer o entrelace da Lei N. 10.639/2003 na disciplina de Ciências, relatando que suas formações iniciais não lhe deram suporte para o trato com a temática, que durante a formação inicial, em nenhum momento tiveram contato com a temática e como professores na EMEFRN jamais foram oferecidos formações continuadas que dialogam sobre a legislação vigente.

Uma ausência de formação sólida e coerente, torna-se um obstáculo para trabalhar e propor atividades referentes à diversidade nas escolas, e dificultando a abordagem da cultura dos africanos dentro do currículo e na disciplina de Ciências (VERRANGIA, 2009). O entrelace da História e Cultura Afro-brasileira e Africana com a educação em Ciências, desencadeia uma educação que respeita a diversidade cultural brasileira, assim, o ensino de Ciências também tem o papel de enfatizar no seu currículo as diversas heranças e hábitos sobre o negro, valorizando toda a historicidade do Continente Africano (VERRANGIA; SILVA, 2010).

O último encontro formativo evidenciou que todo o processo de formação foi benéfico na constituição enquanto professores de Ciências da EMEFRN, por meio das narrativas, identificou-se que a Lei N. 10.639/2003 surgiu para abrir debates urgentes e 
primordiais na educação básica, igualmente expressaram que saíam da formação satisfeitos, pois antes dos momentos formativos realizados, não concebiam como fazer a relação da sua área com a temática.

\section{Referências}

BEZERRA NETO, J. M. Napoleão e a presença africana na Amazônia. Revista Estudos Amazônicos. vol. III, $\mathrm{n}^{\circ}$ 1, p. 119-124, 2008. Disponível em: << https://www.scielo.br/scielo.php?script=sci_arttext\&pid=So10190742018000100202\&lng=pt\&nrm=iso >. Acesso em 17 abril. 2018.

BRASIL, Ministério da Educação. Conselho Nacional de Educação. Define as Diretrizes Curriculares Nacionais para a Formação Inicial de Professores para a Educação Básica e institui a Base Nacional Comum para a Formação Inicial de Professores da Educação Básica (BNC-Formação), 2019. Disponível em: << https://abmes.org.br/arquivos/legislacoes/Resolucao-CNE-CEB-O02-2019-1220.pdf $>$. Acesso em 18 abr. 2020.

CACHAPUZ, António et al. A necessária renovação do ensino das Ciências. São Paulo: Cortez, 2005.

CANEN, A. A pesquisa multicultural como eixo na formação docente: potenciais para a discussão da diversidade e das diferenças. Ensaio: aval. pol. públ. Educ., Rio de Janeiro, v. 16, n. 59, p. 297-308, abr./jun. 2008. Disponível em: << https://www.scielo.br/pdf/ensaio/v16n59/v16n59ao8.pdf >. Acesso em 28 abril. 2018.

CLANDININ, D. J.; CONNELLY, F. M.. Pesquisa narrativa: experiência e história em pesquisa qualitativa. Tradução: Grupo de Pesquisa Narrativa e Educação de Professores ILEEI/UFU. Uberlândia: EDUFU, 2011.

COELHO, W. N. B. A cor ausente: um estudo sobre a presença do negro na formação de professores - Pará, 1970-1989. 2005. 253 f. Tese (Doutorado em Educação) Universidade Federal do Rio Grande do Norte, Natal, 2005.

COELHO, W. N. B. A lei n. 10.639/2003 no ensino fundamental. In: COELHO, COELHO, W. N. B.; MAGALHÃES, A. D. T. V. (Orgs). Educação para a diversidade: olhares sobre a educação para as relações étnico-raciais. Belo Horizonte: Mazza edições, 2010, p. 18-39. 
COELHO, W. N. B. C.; M. C.; NASCIMENTO, I. P. Práticas pedagógicas de trabalho com relações étnico-raciais na escola na perspectiva da Lei no 10.639/o3 /

Nilma Lino Gomes (org.). 1. ed. - Brasília: MEC: Unesco, 2012.

COROZZA, M. J.; PEDRANCINI, V. D. Interações discursivas e a elaboração dos conceitos de raça e espécie em aulas de Biologia. Revista Electrónica de Enseñanza de las Ciencias. v. 13, n. 1, 2014. Disponível em: <<

http://reec.uvigo.es/volumenes/volumen13/REEC_13_1_2_ex699.pdf>. Acesso em 29 set. 2018.

CRUZ, A. C. J. O lugar da história e cultura africana e afro-brasileira nos debates contemporâneos do currículo brasileiro. Revista Ensino Interdisciplinar, v. 3, nº . o8, Maio/2017. Disponível em: <<

http://periodicos.uern.br/index.php/RECEI/article/view/2504 >. Acesso em 15 abril. 2017.

FOUREZ, G. Crise no Ensino de Ciências? Investigações em Ensino de Ciências, Rio Grande do Sul, v. 8, n. 2, p. 109-123, 2003. Disponível em: << https://www.if.ufrgs.br/cref/ojs/index.php/ienci/article/view/542/337 >. Acesso em 22 maio. 2018.

GARCIA, A. Encontros e processos formativos: uma conversa sobre currículos e estágio na formação de professores. Cadernos de Pesquisa em Educação - PPGE/UFES, Vitória, ES. a. 10, v. 19, n. 38, p. 11-34, jul./dez. 2013. Disponível em: << https://www.periodicos.ufes.br/educacao/article/view/7890 >. Acesso em 14 out. 2018.

GOLDENBERG, M. A arte de pesquisar: como fazer pesquisa qualitativa em Ciências Sociais. $8^{\circ}$ edição. Rio de Janeiro: Record, 2004.

GOMES, N. L. A questão racial na escola: desafios colocados pela implementação da Lei 10.639/o3. In: MOREIRA, A. F.; CANDAU, V. M. (Orgs.) Multiculturalismo: diferenças Culturais e Práticas Pedagógicas. 7 ed. Petrópolis, RJ: Vozes, 2011.

GOMES, N. L. Relações Étnico-Raciais, educação e descolonização dos currículos. Currículo sem Fronteiras, v.12, n.1, pp. 98-109, Jan/Abr 2012. Disponível em: << http://www.curriculosemfronteiras.org/vol12iss1articles/gomes.pdf >. Acesso em 18 maio. 2018.

GONÇALVES, T. V. O. A pesquisa narrativa e a formação de professores: reflexos sobre uma prática formadora: CHAVES, S. N. C.; BRITO, M. R. (Orgs.). Formação e docência: perspectiva da pesquisa narrativa e autobiográfica: Belém: CEJUP, 2011. 
HAGE, S. M. Currículo: composições temáticas e referenciais. In: CORRÊA, P. S. A. (Org.). A educação, o currículo e a formação de professores. Belém: EDUFPA, 2006.

MATOS, M. C. G. Movimento de (trans)formação na Amazônia legal: a educação em Ciências e Matemática. 2015, 183f. Tese (Doutorado em Educação em Ciências e Matemáticas) - Universidade Federal do Pará, Instituto de Educação Matemática e Científica, Programa de Pós-graduação em Educação em Ciências e Matemáticas, Belém, 2015.

MATTHEWS, M. Historia, Filosofia y enseñanza de lasciencias: laaproximaciónactual. Enseñanza de las Ciencias, v. 12, n. 02, p. 22, 1994. Disponível em: < < https://www.raco.cat/index.php/Ensenanza/article/view/21364 >. Acesso em o9 maio. 2018.

MAUÉS, J. Currículo: composições temáticas e referenciais. In: CORRÊA, P. S. A (Org.). A educação, o currículo e a formação de professores. Belém: EDUFPA, 2006.

MORAES, R.; GALIAZZI, M. C. Análise Textual Discursiva. Ijuí: UNIJUÍ, 2007. NÓVOA, A. (Org.). Vidas de Professores. $2^{\circ}$ edição. Portugal. Porto Editora: 2013.

OLIVEIRA JÚNIOR, Waldemar Borges de. A educação das relações étnico-raciais: uma experiência formativa com professores de Ciências do Ensino Fundamental. 2018, 186f. Dissertação (Mestrado em Docência em Educação em Ciências e Matemáticas), Programa de Pós-graduação em Docência em Educação em Ciências e Matemáticas, Universidade Federal do Pará, Belém, 2018.

PAULA, B. X.; GUIMARÃES, S. 10 anos da lei federal $n^{0}$ 10.639/2003 e a formação de professores: uma leitura de pesquisas científicas. Educação e Pesquisa. São Paulo, v. 40, n. 2, p. 435-448, abr./jun. 2014. Disponível em: << https://www.scielo.br/pdf/ep/v40n2/v40n2a09.pdf>. Acesso em 17 agosto. 2018.

RODRIGUES, A. L. C. Novas práticas em informação e conhecimento. Curitiba, v. 1, n. 2, p. 10-25, jan./dez. 2012. Disponível em: $<<$ https://revistas.ufpr.br/atoz/article/view/41309/25222>. Acesso em o8 março. 2018.

SILVA, P. B. G. Aprender, ensinar e relações étnico-raciais no Brasil. Educação. Porto Alegre/RS, ano XXX, n. 3 (63), p. 489-506, set./dez. 2007. Disponível em: << https://revistaseletronicas.pucrs.br/ojs/index.php/faced/article/view/2745 >. Acesso em 02 maio. 2018. 
SOUZA, B. C. M. C.; AYRES, A. C. M. Educação das relações étnico-raciais: implicações no ensino de ciências em escolas do Rio de Janeiro. Revista Aproximado. v. 2. $\mathrm{n}^{\mathrm{O}} 3$. 2016. Disponível em: <<

https://ojs.latic.uerj.br/ojs/index.php/aproximando/article/view/37 >. Acesso em 11 junho. 2018.

SOUZA, E. C. Memórias (Auto)Biográfica e Formação. In: CHAVES, S. N. C.; BRITO, M. R. (Orgs.). Formação e docência: perspectiva da pesquisa narrativa e autobiográfica: Belém: CEJUP, 2011.

THIOLLENT, Michel. Metodologia da pesquisa-ação. São Paulo: Cortez: Autores Associados, 1986.

VERRANGIA, D. A educação das relações étnico-raciais no ensino de Ciências: diálogos possíveis entre Brasil e Estados Unidos. 2009, 322f. Tese (Doutorado em Educação), Centro de Educação e Ciências Humanas, Programa de Pós-Graduação em Educação, Universidade Federal de São Carlos, São Carlos, 2009.

VERRANGIA, D. A formação de professores de ciências e biologia e os conhecimentos tradicionais de matriz africana e afro-brasileira. Revista Internacional de Investigaciónen Educación, 6 (12) Ediciónespecial Enseñanza de lasciencias y diversidad cultural, 105-11, 2013. Disponível em: <<

https://dialnet.unirioja.es/servlet/articulo?codigo=4774281 >. Acesso em 14 agosto. 2017.

VERRANGIA, D. Conhecimentos tradicionais de matriz africana e afro-brasileira no ensino de Ciências: um grande desafio. Revista África e Africanidades - Ano 2 - n. 8, fev. 2010. Disponível em: $<<$

https://www.africaeafricanidades.com.br/documentos/conhecimentos_tradicionais_m atriz_afro-brasileira_ensino_ciencias.pdf >. Acesso em 29 agosto. 2017.

VERRANGIA, D. Criações docentes e o papel do ensino de Ciências no combate ao racismo e a discriminações. Educ. foco, Juiz de Fora, v. 21 n. 1, p. 79-103 mar. 2016. Disponível em: << https://periodicos.ufjf.br/index.php/edufoco/article/view/19657>. Acesso em 20 agosto. 2017.

VERRANGIA, D.; SILVA, P. B. G. Cidadania, relações étnico-raciais e educação: desafios e potencialidades do ensino de Ciências. Educação e Pesquisa, São Paulo, v. 36, n.3, p. 705-718, set./dez. 2010. Disponível em: $<<$

https://periodicos.ufjf.br/index.php/edufoco/article/view/19657>. Acesso em 05 jul. 2017. 
ZEICHNER, K. A formação reflexiva de professores: Ideias e Práticas. Lisboa: Educa Professor, 1993.

\section{Sobre os autores}

Waldemar Borges de Oliveira Júnior: Possui Graduação em Licenciatura em Ciências Naturais pela Universidade Federal do Pará (UFPA/2015), Especialização em Relações Étnico-raciais para o Ensino Fundamental (UFPA/2016) e Mestrado em Docência em Educação em Ciências e Matemática (PPGDOC/IEMCI/UFPA/2018). Atualmente é Doutorando em Educação em Ciências e Matemáticas (PPGECM/IEMCI/UFPA). É integrante do Núcleo de Estudos e Pesquisas sobre Formação de Professores e Relações Étnico-Raciais (Núcleo GERA-NEAB/UFPA). É membro da Associação Brasileira de Pesquisa em Educação em Ciências (ABRAPEC), da Associação Nacional de Pós-graduação e Pesquisa em Educação (ANPED) e da Associação Brasileira de Pesquisadores/as Negros/as (ABPN). Atuou como professor externo da Faculdade de Ciências Naturais (UFPA/Campus Universitário Tocantins-Cametá). Foi Coordenador Local do Plano Nacional de Formação de Professores da Educação Básica (PARFOR/UFPA/Campus Tocantins-Cametá). Têm experiência na áre de Educação com ênfase nos seguintes temas: Processo de Ensino e Aprendizagem no Ensino de Ciências; Formação de Professores e Relações Etnico-Raciais. E-mail: waldemarjuniorcn@gmail.com

Maria da Conceição Gemaque de Matos: Possui graduação em Licenciatura em Ciências pela Universidade Federal do Pará (1977), graduação em Licenciatura Plena em Física pela Universidade Federal do Pará (1979), mestrado em Educação pela Universidade Federal do Pará (2010) e doutorado em Educação em Ciências e Matemáticas pela Universidade Federal do Pará (2015). Atualmente é colaborador da Universidade Federal do Pará, professor convidado da Universidade Federal do Pará, professor convidado da Universidade Federal do Pará, professor convidado da Universidade Federal do Pará, professor substituto da Universidade Estadual do Pará, professor orientador - Mestrado Nacional Profissional em Ensino de Física e professora colaboradora -Programa de Pós-Graduação em Docência em Educação em Ciências e Matemática. Tem experiência na área de Física (Mecânica, Hidrologia, Termologia Ondulatória, Óptica, Eletricidade e Magnetismo, Física Moderna), Na área ensino e formação de professores de Física, atuando principalmente nos seguintes temas: formação docente, reformas educativas, currículo, educação tecnológica, formação de professores, educação em ciências e currículo, educação e tecnologias. E-mail cgemaquematos@gmail.com 